\title{
The Divergent Roles of Secreted Frizzled Related Protein-1 (SFRP1) in Lung Morphogenesis and Emphysema
}

\author{
Robert Foronjy, ${ }^{*}$ Kazushi Imai, ${ }^{*}$ Takayuki Shiomi, ${ }^{*}$ \\ Becky Mercer, ${ }^{*}$ Piotr Sklepkiewicz, ${ }^{*}$ \\ Jincy Thankachen, ${ }^{*}$ Peter Bodine, ${ }^{\dagger}$ \\ and Jeanine D'Armiento*

\begin{abstract}
From the Department of Medicine," Columbia University, New York, New York; and the Women's Health and Musculoskeletal
\end{abstract} \\ Biology, ${ }^{\dagger}$ Wyeth Research, Collegeville, Pennsylvania
}

Developmentally expressed genes are believed to play a central role in tissue repair after injury; however, in lung disease their role has not been established. This study demonstrates that SFRP1, an inhibitor of Wnt signaling normally expressed during lung embryogenesis, is induced in the lungs of emphysema patients and in two murine models of the disease. SFRP1 was found to be essential for alveolar formation as $S f r p 1^{-/-}$mice exhibited aberrant Wnt signaling, mesenchymal proliferation, and impaired alveoli formation. In contrast, SFRP1 activated ERK and up-regulated MMP1 and MMP9 without altering TIMP1 production when expressed in human lung epithelial cells. These findings demonstrate that SFRP1 promotes normal alveolar formation in lung development, although its expression in the adult up-regulates proteins that can cause tissue destruction. Thus, SFRP1 induction during tissue injury is unlikely to contribute to the repair response but rather is a participatory factor in the pathogenesis of emphysema and tissue destruction. (Am J Pathol 2010, 177:598-607; DOI: 10.2353/ajpath.2010.090803)

Lung morphogenesis and repair involve complex interactions between cells of endodermal and mesodermal origin. The ultimate goal of these interactions is to generate or restore an alveolus that effectively exchanges gases between the circulation and alveolar space. Importantly, the induction of genes linked to development has been observed in postinjury repair responses in several adult organs. ${ }^{1-3}$ It is theorized that mechanisms of repair use these genes to recapitulate fundamental strategies of normal development and thus restore proper organ function. ${ }^{4}$ In con- flict with this theory, studies have shown that liver regeneration does not require transcription factors known to be important in liver development. ${ }^{5}$ Furthermore, a study indicated that the reversion to a developmental pattern in the adult gastrointestinal tract could actually trigger dysfunction of the digestive system. ${ }^{6}$ Therefore, the beneficial role of the re-expression of developmentally regulated genes in tissue repair is likely organ specific.

Wnt proteins, critical molecules in lung development, are also up-regulated in adult diseases of the lung. ${ }^{7}$ Wnt signals through the canonical pathway involving $\beta$-catenin and through noncanonical pathways involving protein kinase $C$ $(\mathrm{PKC})^{8}$ and mitogen-activated protein kinase (MAPK)8 (also known as JNK1). ${ }^{9}$ Through stimulation of these signaling pathways, the WNTs modulate important processes involved in lung morphogenesis and repair including cell proliferation, ${ }^{10}$ migration, ${ }^{11}$ and differentiation. ${ }^{12}$ Secreted frizzled related proteins (SFRPS) bind soluble Wnts and inhibit interaction with the frizzled receptor ${ }^{13}$ thereby antagonizing their action. Though SFRPs are expressed in the lung during embryogenesis, ${ }^{14}$ their contribution to lung development has not been determined. Moreover, there are virtually no data regarding the role of SFRPs on noncancer disease states of the adult lung despite the assumption that these molecules are central to the repair of the tissue. ${ }^{15}$ The present study identified the selective induction of SFRP1 in the lungs of emphysema patients. Given the known role of Wnt signaling on lung development and repair, analyses were conducted to determine the specific role of SFRP1 on lung morphogenesis and to evaluate how SFRP1 influenced biological responses linked to the development of cigarette smokeinduced emphysema.

Supported by the Flight Attendant Medical Research Institute (FAMRI) and National Institutes of Health grant HL086936-01.

R.F. and K.I. contributed equally to this work.

Accepted for publication April 13, 2010.

P.B. is a full-time employee of Pfizer, Inc., which acquired Wyeth in October 2009. He also holds stock in Pfizer. None of the other authors declare any relevant financial relationships.

Address reprint requests to Jeanine D'Armiento, M.D., Ph.D., 630 West 168th Street, P\&S 9-449, New York, NY 10032. E-mail: jmd12@columbia.edu. 
Table 1. PCR Primers

\begin{tabular}{|c|c|c|c|c|}
\hline Species & Genes & & Primer Sequence & Annealing temperature $\left({ }^{\circ} \mathrm{C}\right)$ \\
\hline \multirow[t]{11}{*}{ Human } & SFRP1 & Forward & 5'-TACAAGAAGATGGTGCTGCC-3' & 52 \\
\hline & \multirow[t]{2}{*}{ SFRP2 } & Forward & 5'-TCTTCCTCTTTGGCCAGCCC-3' & \multirow[t]{2}{*}{58} \\
\hline & & Reverse & $5^{\prime}-$ TCACATCAATTTGGAGCTTC- $3^{\prime}$ & \\
\hline & \multirow[t]{2}{*}{ SFRP3 } & Forward & $5^{\prime}-$ TCTGCACCATTGACTTCCAG- $3^{\prime}$ & \multirow[t]{2}{*}{52} \\
\hline & & Reverse & 5'-TTAGAATCTCCTTCACCTCC-3' & \\
\hline & \multirow[t]{2}{*}{ SFRP4 } & Forward & $5^{\prime}-$ TCCTGGCCATCGAGCAGTAC-3' & \multirow[t]{2}{*}{58} \\
\hline & & Reverse & $5^{\prime}$-GATGAGGACTTGAAGATCTC-3' & \\
\hline & \multirow[t]{2}{*}{ SFRP5 } & Forward & 5'-ACTCGGATACGCAGGTCTTC-3' & \multirow[t]{2}{*}{58} \\
\hline & & Reverse & $5^{\prime}-$ TTCTTGTCCCAGCGGTAGAC-3' & \\
\hline & \multirow[t]{2}{*}{ GAPDH } & Forward & $5^{\prime}-$ TTCCACCCATGGCAAATTCC-3' & \multirow[t]{2}{*}{50} \\
\hline & & Reverse & $5^{\prime}-$-TTTCTAGACGGCAGGTCAGG-3' & \\
\hline \multirow[t]{8}{*}{ Mouse } & \multirow[t]{2}{*}{ Sfrp1 } & Forward & 5'-AGACCATGGCAGAGGTGAAG- $3^{\prime}$ & \multirow[t]{2}{*}{58} \\
\hline & & Reverse & $5^{\prime}$-CCGCCCCAGTATCACTTAAA-3' & \\
\hline & \multirow[t]{2}{*}{ Wnt5a } & Forward & 5'-GGTGCCATGTCTTCCAAGTT-3' & \multirow[t]{2}{*}{51} \\
\hline & & Reverse & $5^{\prime}-$ CAGCACGTCTTGAGGCTACA-3' & \\
\hline & \multirow[t]{2}{*}{ Wnt10b } & Forward & 5'-TGCTTTCTCCTTCTCCATGC-3' & \multirow[t]{2}{*}{57} \\
\hline & & Reverse & 5'-GATTTCACCTGACCCCTGAA- $3^{\prime}$ & \\
\hline & \multirow[t]{2}{*}{ Gapdh } & Forward & $5^{\prime}$-ATGCATCCTGTACCACCAAC- $3^{\prime}$ & \multirow[t]{2}{*}{56} \\
\hline & & Reverse & 5'-TGGTCCTCTGTGTAAGCAAG- $3^{\prime}$ & \\
\hline
\end{tabular}

\section{Materials and Methods}

\section{Human Lung Tissue Samples}

Lung tissue explants from six unrelated patients with emphysema were obtained under consent at Columbia Presbyterian Medical Center from recipient lungs during transplant or lung volume reduction procedures. Normal samples were from accidental death victims or unused donor lungs harvested for transplant. All of the samples were obtained from New York-Presbyterian Hospital with the approval by Institutional Review Board of Columbia University.

\section{Sfrp $1^{-1-}$ Mice}

The generation of the Sfrp 1 knockout $\left(S f r p 1^{-1-}\right)$ mice in the C57BL/6(albino)-129SvEv ${ }^{\text {brd }}$ background has been previously reported. ${ }^{16}$

\section{Cells}

Human small airway epithelial (SAE) cells were purchased from Lonza Walkersville Inc. (Walkersville, MD). A549 cells were obtained from ATCC (American Tissue Culture Collection, Manassas, VA).

\section{Wnt Signaling Analyses}

RT-PCR was performed on human and mouse samples using specific primer sets (Table 1). After the reverse transcription reaction of total RNA using SuperScript II (Invitrogen Corporation, Carlsbad, CA), PCR reaction was performed at the appropriate annealing temperature. Amplicons were analyzed on a $2 \%$ agarose gel. For Northern analyses of mouse lung, $10 \mu \mathrm{g}$ of lung tissue RNA was separated on a $1.2 \%$ agarose-formaldehyde gel and transferred to nylon membrane which was then exposed to radiolabeled Sfrp1 and glyceraldehyde-3- phosphate dehydrogenase (Gapdh) cDNA probes. Membranes were hybridized with a 28S rRNA oligonucleotide probe labeled with $\left(\gamma_{-}{ }^{32}\right.$ P) ATP to control for loading. Using specific primers and probe (Applied Biosystems Inc., Foster City, CA), quantitative PCR for mouse Wnt5a, Wnt7b, MMP9, and Actin was performed on cDNA prepared from the lung mRNA of wild-type and Sfrp ${ }^{-1-}$ mice at $14.5,16.5$, and 18.5 days postcoitum (dpc) $(n=$ 4 in each group). Western blot for WNT5A (SC-23698), WNT10B (SC-7432), SFRP1 (SC-7425; Santa Cruz Biotechnology, Inc., Santa Cruz, CA), MAPK3 and MAPK1 (also known as ERK1 and ERK2), phospho-ERK1/2 and phospho-JNK1 (Cell Signaling Technology, Inc., Danvers, MA) was performed on the lung tissue homogenates of wild-type mice at $14.5 \mathrm{dpc}$. Western blot for $\beta$-catenin (Cell Signaling Technology, Inc.) was performed on nuclear protein fractions from the embryonic and newborn mice. Nucleophosmin (Invitrogen Corporation) was used as a loading control. Western blot for SFRP1 was performed on the human lung tissue homogenates of six emphysema and five normal lungs as per standard protocol.

\section{Mouse Lung Injury Models}

All of the experiments were conducted according to Institutional Animal Care and Use Committee-approved protocol.

\section{Acute Bacterial Inflammation Model}

Three-month-old C57BL/6 mice were injected intraperitoneally with $50 \mu \mathrm{g}$ of lipopolysacharride (LPS; SigmaAldrich Corp., St. Louis, MO) in sterile PBS. Control littermates were treated with sterile PBS alone. After 16 hours, animals were sacrificed by isoflurane overdose followed by cervical dislocation. 


\section{Chronic Smoke Exposure Model}

C57BL/6 mice were exposed to air (controls) or cigarette smoke (6 hours/day, 5 days/week) in a specially designed full-body smoke exposure chamber (Teague Enterprises, Woodland, CA) for one day, two weeks, or four months as per standard laboratory protocol. ${ }^{17}$ The mice were sacrificed twelve hours after smoke exposure.

\section{Collagenase Transgenic Emphysema Model}

Generation of the MMP1 transgenic mice has been previously reported. ${ }^{18}$

\section{Hyperoxia Lung Injury Model}

C57BL/6 mice were exposed to 85\% oxygen for three days in a plexiglass container. The mice were provided food and water ad libitum.

\section{SFRP1 Administration to Human SAE Cells}

SAE cells in six-well plates were grown to 70 to $80 \%$ confluence and then treated with recombinant SFRP1 protein (R\&D Systems, Inc., Minneapolis, MN) at a concentration of 0,20 , and $100 \mathrm{ng} / \mathrm{ml}$ for 3 hours $(n=6)$ or $10 \mathrm{ng} / \mathrm{ml}$ for 48 hours $(n=6)$. The control cells were treated with $10 \mu \mathrm{g} / \mathrm{ml}$ of bovine serum albumin (Sigma-Aldrich Corp.) for 3 or 48 hours $(n=6)$. Each experiment was performed in duplicate. Matrix metalloproteinase (MMP)1, MMP9, and TIMP1 protein levels were determined by ELISA of the media (Millipore, Billerica, MA). Western blots for basal and active ERK-1/2 (Cell Signaling Technology, Inc.) and actin (Santa Cruz Biotechnology, Inc.) were performed on protein from SAE and A549 cell monolayers with or without treatment with human SFRP1 protein.

\section{SFRP1 Adeno-Associated Viral Vectors}

The rAAV2 vector plasmids carrying the expression cassettes of Sfrp1, Wnt10b, and GFP under the influence of the SV40 promoter were constructed as per established protocols. ${ }^{19}$ rAAV2 vectors were added at concentrations of $10^{8}$ to $10^{10}$ vector genome (vg) to T-25 flasks with SAE cells grown to $60 \%$ confluency. Twenty-four hours after transduction this media was exchanged with fresh growth media. After 24 hours, MMP1 protein levels in the media were determined by ELISA (Millipore).

\section{Lung Histological Analyses}

Immunofluorescent studies for Sfrp1 (SC-13939), WNT5A (SC-30224), and WNT10B (SC-25524; Santa Cruz Biotechnology, Inc.) and immunohistochemistry for Clara Cell 10 protein (SC-25555; Santa Cruz Biotechnology, Inc.) were conducted on lung tissue sections as per standard laboratory protocol. ${ }^{20}$ Proliferating cells were detected using a PCNA monoclonal antibody (PCNA staining kit, Invitrogen Corporation). For smooth muscle actin staining, anti- $\alpha$-smooth muscle actin antibody (Dako North America Inc., Carpinteria, CA) were used.

\section{Lung Morphometry and Compliance}

Morphometric analyses were conducted on H\&E-stained slides of eight mice in each group as previously outlined by our laboratory. ${ }^{20}$ Compliance was determined using the flexiVent apparatus (SCIREQ Scientific Respiratory Equipment Inc., Montreal, Canada) as per our previously published protocol. ${ }^{17}$

\section{Gelatin Zymography}

Equal amounts of protein were loaded and gelatin zymography was performed on this lung homogenate as previously described. ${ }^{21}$

\section{Lung Lavage Cellularity}

Lung lavage cell count and differentials were performed on control, smoke-exposed, and LPS-treated mice as per standard laboratory protocol. ${ }^{20}$

\section{Statistical Analyses}

Data are expressed as the mean \pm SD. One- and twoway analysis of variance measures were conducted using commercially available software (Prism 5, Graphpad Software Inc., La Jolla, CA).

\section{Results}

\section{SFRP Expression in Human Emphysema}

The lung expression pattern of the SFRP family members in human emphysema and normal lung tissue was determined through RT-PCR analysis. SFRP1 was expressed in the lungs of emphysema patients but not in normal lung tissue (Figure 1A). SFRP2 and SFRP5 (data not shown) were not detected in any of the samples, and FRZB (also known as SFRP3) was detected in only one of four emphysema lungs and in none of the normal lung samples (Figure 1A). SFRP4 was detected in all of the emphysema and normal lung samples (data not shown). SFRP1 was not detectable by Western blot in normal lung tissue; however, it was present in lung tissue samples from four emphysema patients (Figure 1B). Immunohistochemistry studies identified expression of Sfrp1 in the epithelial cell of the emphysema lung (Figure 1C).

\section{Sfrp1 Is Expressed in Mice during Hyperoxic Lung Injury and Emphysema, but not During Acute Inflammation}

Because SFRP1 was expressed in human emphysema we then investigated whether Sfrp1 could be up-regulated under several distinct conditions of lung injury in mice using Northern blot analysis (Figure 1D). The expression of Sfrp1 was significantly increased under hyperoxic conditions ( $85 \%$ oxygen inhalation for 3 to 5 days), in a collagenase-induced mouse model of emphy- 
A

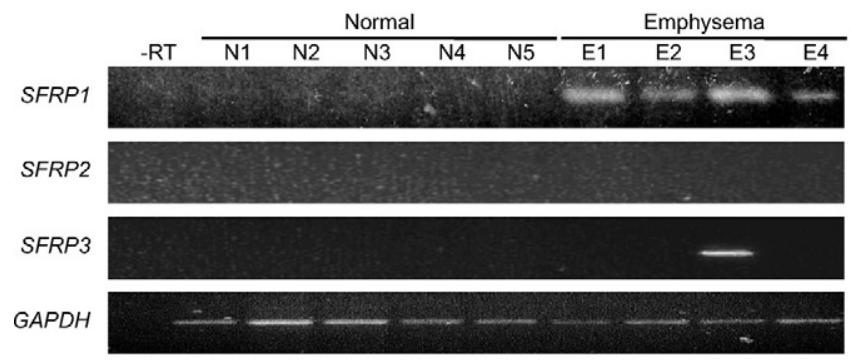

C

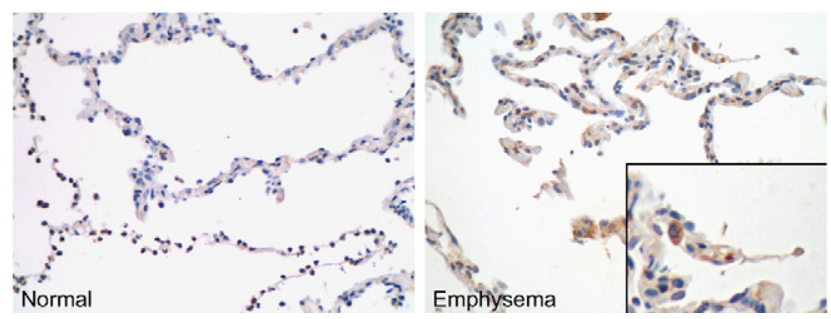

B

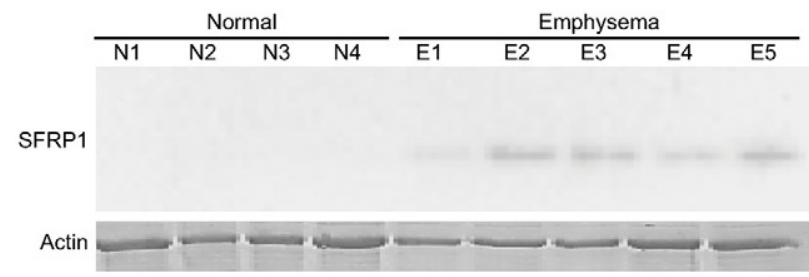

D

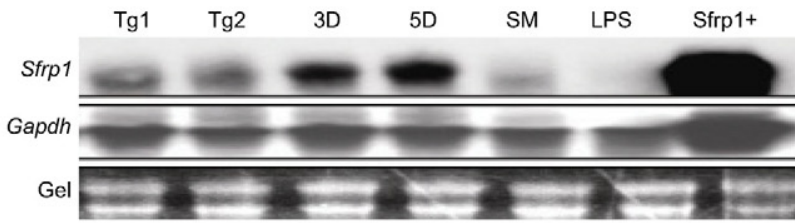

Figure 1. SFRP1 is up-regulated in human emphysema and in animal models of the disease. A: Using specific primers for human SFRPs1-5, RT-PCR analysis was performed on RNA isolated from the lung tissue of human normal controls (N1-5) and emphysema subjects (E1-4). RT-PCR for GAPDH was used as an internal control. SFRP1 was expressed only in the emphysema samples. B: Western blot analysis for human SFRP1 was performed on lung tissue protein from normal controls (N1-4) and emphysema subjects (E1-5). Actin Western blot was performed to confirm equal protein loading. SFRP1 was expressed only in the emphysema samples. C: Immunohistochemistry studies exhibited negligible staining in the normal human lung samples with the anti-SFRP1 antibodies. In contrast, the epithelial cells stained positively in the human emphysematous lung samples. Inset: High-power view of emphysema tissue stained with anti-SFRP1 antibodies; original magnification, $\times 40$. D: Northern blot of Sfrp1 expression in distinct mouse models of lung injury: MMP1 transgenic mice (Tg1 and Tg2), hyperoxia (three or five days of exposure to $85 \%$ oxygen; 3D and 5D, respectively), mice exposed to chronic cigarette smoke for six months (SM), mice injected in the peritoneum with $50 \mu \mathrm{g}$ of LPS and a positive control which was RNA isolated from human HEK cells stably transfected with mouse Sfrp1 cDNA (Sfrp1+). The membrane was stripped and reprobed with a probe for GAPDH (middle). The bottom panel shows the ethidium bromide-stained 1.5\% agarose formaldehyde gel. Sfrp1 was expressed in the diseased models (emphysema and hyperoxia) but not in LPS-treated lungs.

sema and after cigarette smoke exposure. In contrast, when the mice were treated with an intraperitoneal injection of LPS, Sfrp1 was not induced in the lung (data not shown). This was despite the fact that LPS caused an acute increase in lung lavage cellularity $(25.8 \pm 5.87$ control versus $48.8 \pm 5.31$ LPS-treated; $n=5, P=$ $0.0161)$. This indicates that Sfrp1 expression is not a generalized reaction to lung inflammation.

\section{SFRP1 Increases MMP Expression in Lung Epithelial Cells}

The tissue destruction in emphysema ultimately results from an increase in protease production. ${ }^{22}$ Studies in mice $^{18,23}$ and human ${ }^{24}$ have implicated the proteases MMP1 and MMP9 in emphysema and shown the aberrant expression of these enzymes destroy the lung over time. To determine whether SFRP1 modulates MMP production, we measured MMP levels in human SAE cells treated with SFRP1. As shown in Figure 2, A and B, treatment with purified SFRP1 increased MMP1 and MMP9 protein levels in SAE cell media but did not affect TIMP1 (the natural inhibitor) protein levels. The treatment of SAE cells with SFRP1 activated ERK1/2, which is known to regulate MMP expression in SAE cells treated with cigarette smoke (Figure $2 \mathrm{C})^{23}$ and MAPK8. Thus, SFRP1 replicates a biological process linked to emphysema formation. ${ }^{18}$ Consistent with our results for SFRP1 protein treatment, administration of AAV2 vectors ex- pressing SFRP1 significantly increased MMP1 protein level compared with AAV2-Wnt10b and AAV2-gfp treated cells (Figure 2D). In addition, mice treated with AAV2 expressing SFRP1 exhibited increased expression of MMPs in lung tissue homogenates (Figure 2E). These animals did not develop emphysema (data not shown) because the vector was only expressed for one month and MMP-induced emphysema develops over a long period of time. ${ }^{18,24}$

\section{SFRP1 and WNTs Expression during Lung Embryogenesis}

The above data demonstrate a link between SFRP1, MMPs, and emphysema, but Wnt signaling and MMP expression are also known to play a fundamental role in normal development. Therefore, we undertook the following experiments to better understand the role of SFRP1 during lung development so as to potentially gain insight into its function during disease. We first examined the gene expression pattern of Wnt5a, Wnt10b, and Sfrp1 during lung morphogenesis in wildtype mice (Figure 3A) as RT-PCR analysis demonstrated these proteins to be expressed during the same embryonic time point. Both WNT5A and WNT10B play a known role in development ${ }^{25,26}$ and are likely regulated by SFRP1. ${ }^{27}$ All three genes were amplified by RT-PCR in the samples from the embryonic lung tissues between 14.5 to $18.5 \mathrm{dpc}$; however, their ex- 
A

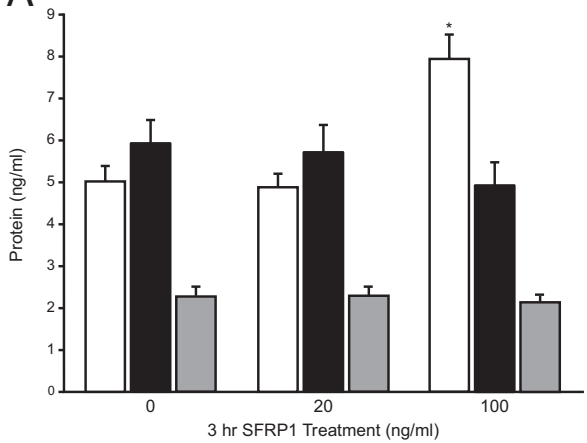

C

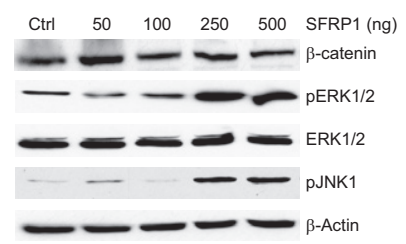

E

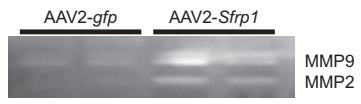

B

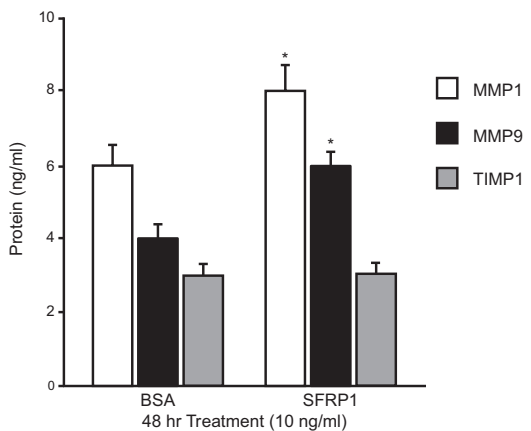

D

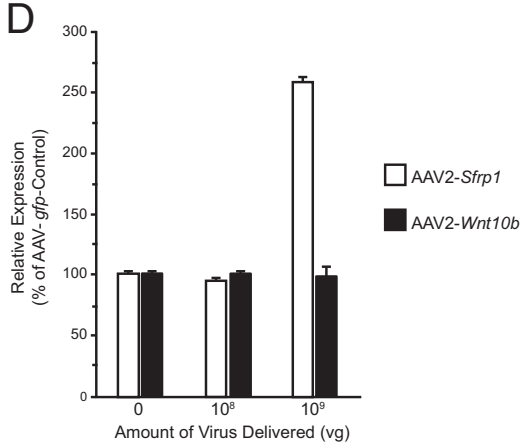

Figure 2. SFRP1 increases the level of MMP1 and MMP9 and activates ERK in lung epithelial cells. A and B: MMP ELISAs performed on culture media harvested from SAE cells treated with SFRP1 or BSA protein for three hours (A) or 48 hours with $10 \mathrm{ng} / \mathrm{ml}$ of either SFRP1 or BSA control protein $(\mathbf{B})$, as indicated. Error bars indicate $\mathrm{SD}\left({ }^{*} P<0.05, n=12\right.$ in all groups). The $y$ axis represents ng of protein per ml of media MMP-1 and MMP-9 levels increased with SFRP1 treatment. C: Human SAE and A549 cells were treated with varying concentrations of human SFRP1 protein. Western blot analyses for phospho-ERK, total ERK, phospho-JNK1, and actin were conducted on the cell lysate. SFRP1 treatment induced the phosphorylation of ERK and JNK. D: Human SAE cells were treated with AAV2 coding Sfrp1, Wnt1Ob, or gfp at concentrations of $10^{8}$ to $10^{10}$ vector genome (vg). Protein levels for MMP1 in the media were determined by ELISA. Data are expressed as a percentage of AAV2-gfp control. E: Gelatin zymography of lung tissues isolated from AAV2$g f p$ and Sfrp1 transfected mice lung. Both MMP2 and MMP9 were up-regulated in Sfrp1 transfected lung. pression was not observed in the postnatal lungs (newborn, 5 days postpartum and 14 weeks) (Figure 3A). Protein levels of these WNT5A, WNT10B, and Sfrp1 were assessed by Western blot analysis. A single protein band of WNT5A, WNT10B, and Sfrp1 was seen in the 14.5-dpc lung extracts but not in the 5-day-postpartum lung extracts (Figure 3B).

\section{Localization of WNT5A, WNT10B, and Sfrp1 in the Developing Lung}

To better understand the relationship between Sfrp1, WNT5A, and WNT10B, immunolocalization studies were undertaken in developing lung tissue samples of wild-type mice. During the early pseudoglandular stage (10.5 dpc), WNT5A and WNT10B were immunolocalized to the epithelium and the surrounding mesenchymal cells. By $12.5 \mathrm{dpc}$, detection of WNT5A persisted in the epithelium and mesenchyme while WNT10B became far more prominent within the epithelial region of the lung. In contrast, Sfrp1 was not detected in the lung during this early pseudoglandular stage. In the mid-pseudoglandular stage, WNT5A staining was prominent in the epithelium and the neighboring mesenchyme at $13.5 \mathrm{dpc}$. Staining became restricted to the distal lung epithelium and mesenchyme by $14.5 \mathrm{dpc}$. In contrast, WNT10B localized primarily to the epithelial cells at $13.5 \mathrm{dpc}$ and $14.5 \mathrm{dpc}$ with scant detection noted in the mesenchymal regions of the lung. Expression of Sfrp1 was first detected within this time period in a pattern that correlated with WNT5A. During the late pseudoglandular stage, WNT5A was detected within the distal epithelium and the surrounding mesenchymal cells at $15.5 \mathrm{dpc}$. This staining became localized primarily to the mesenchyme between the distal epithelial buds by $16.5 \mathrm{dpc}$. WNT10B was ob- served almost exclusively in the distal epithelial cells at 15.5 $\mathrm{dpc}$ and $16.5 \mathrm{dpc}$. As seen with WNT5A, Sfrp1 was detected in the distal epithelial cells and the surrounding mesenchymal cells at $15.5 \mathrm{dpc}$ and $16.5 \mathrm{dpc}$. WNT5A, WNT10B, and Sfrp1 were not observed in the late stage of lung development (17.5 and $18.5 \mathrm{dpc}$, and neonates) (Figure 3C). The known interaction of Sfrp1 with WNT and the correlation of Sfrp1 staining with WNT5A and WNT10B suggest that Sfrp1 is an important regulator of the signaling effects mediated by this protein during embryogenesis.

\section{Impaired Distal Lung Development in the Sfrp1 Knockout Mice}

The detection of Sfrp1 in the distal lung solely between 13.5 and $16.5 \mathrm{dpc}$ and its subsequent absence in the later stages of lung morphogenesis suggested that Sfrp1 could be particularly important for distal lung formation. To determine the role of Sfrp1 on lung morphogenesis, we carefully analyzed developing lung tissue harvested from Sfrp $1^{-1-}$ mice. Gross examination revealed no obvious abnormality in adult lung tissue between these wild-type and Sfrp 1-I- $^{-1}$ mice (data not shown). Further, the knockout animals appeared normal from birth through adulthood (data not shown). However, microscopic examination of adult lung tissue sections revealed that Sfrp $1^{-1-}$ mice developed marked dilation of the alveolar duct of the lung (Figure 4A). Morphometric analysis revealed a significant increase $(P=$ 0.0028 ) in mean linear intercept (MLI) at two months of age in the lungs of knockout mice $(61.0 \pm 11.0 ; n=8)$ compared with wild-type animals (49.0 $\pm 3.0 ; n=8$ ) (Figure 4B). $\mathrm{MLI}$ measurements conducted on animals at six and twelve months of age showed that this abnormality was nonpro- 
A

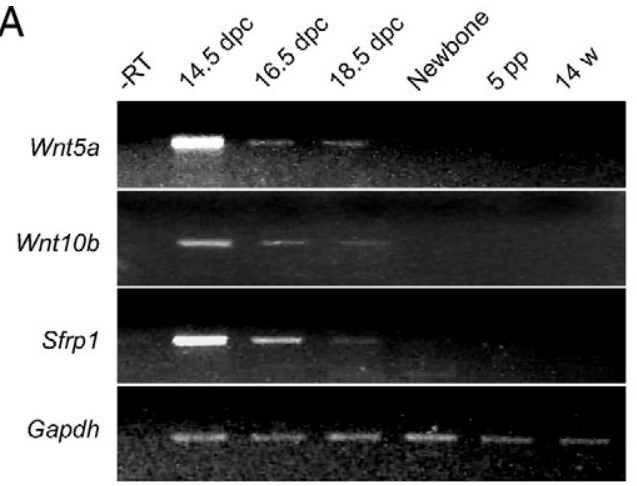

B

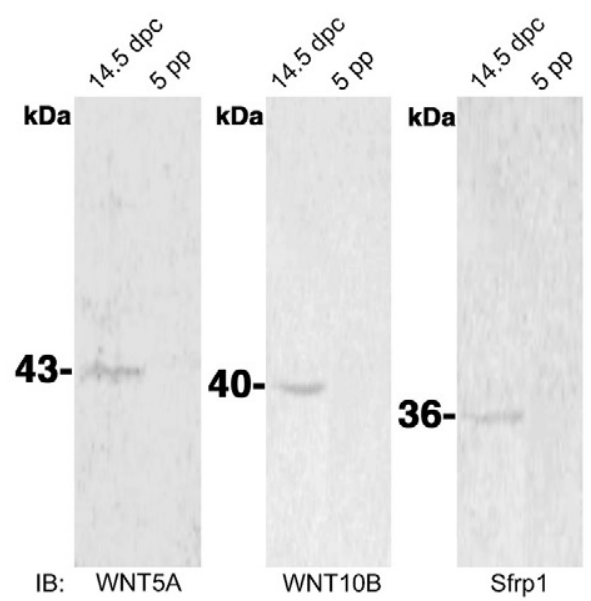

C

$10.5 \mathrm{dpc}$

$12.5 \mathrm{dpc}$

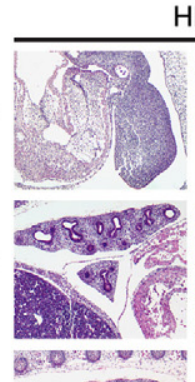

$\mathrm{HE}$
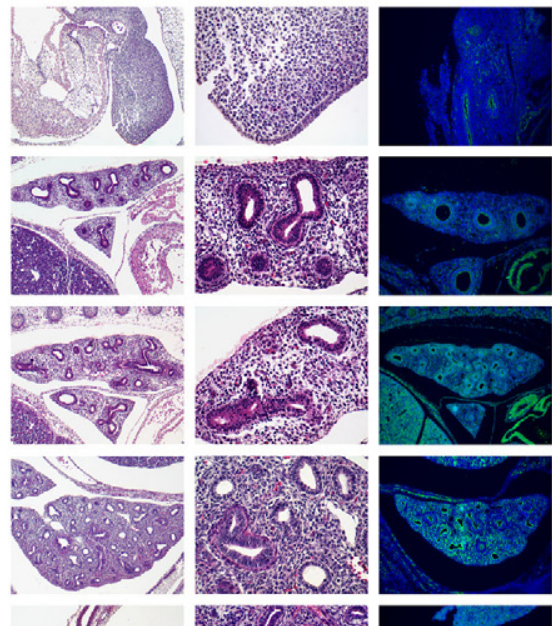

WNT5A
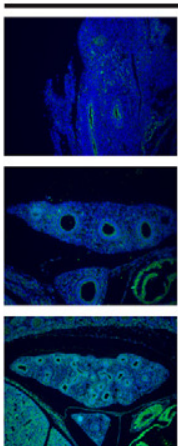

$14.5 \mathrm{dpc}$

$15.5 \mathrm{dpc}$
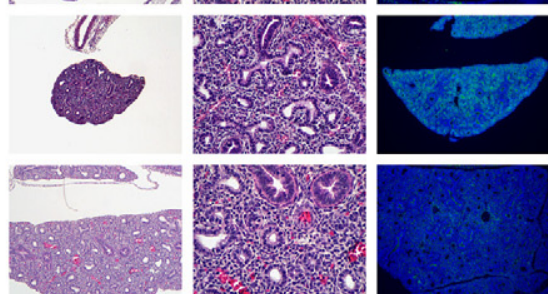

$16.5 \mathrm{dpc}$

$17.5 \mathrm{dpc}$
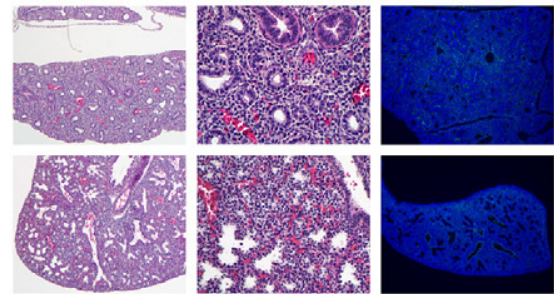

$18.5 \mathrm{dpc}$
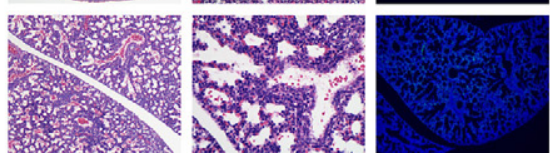
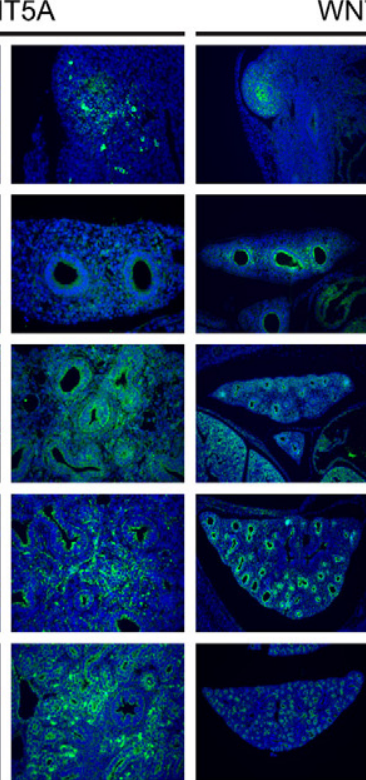

WNT10B
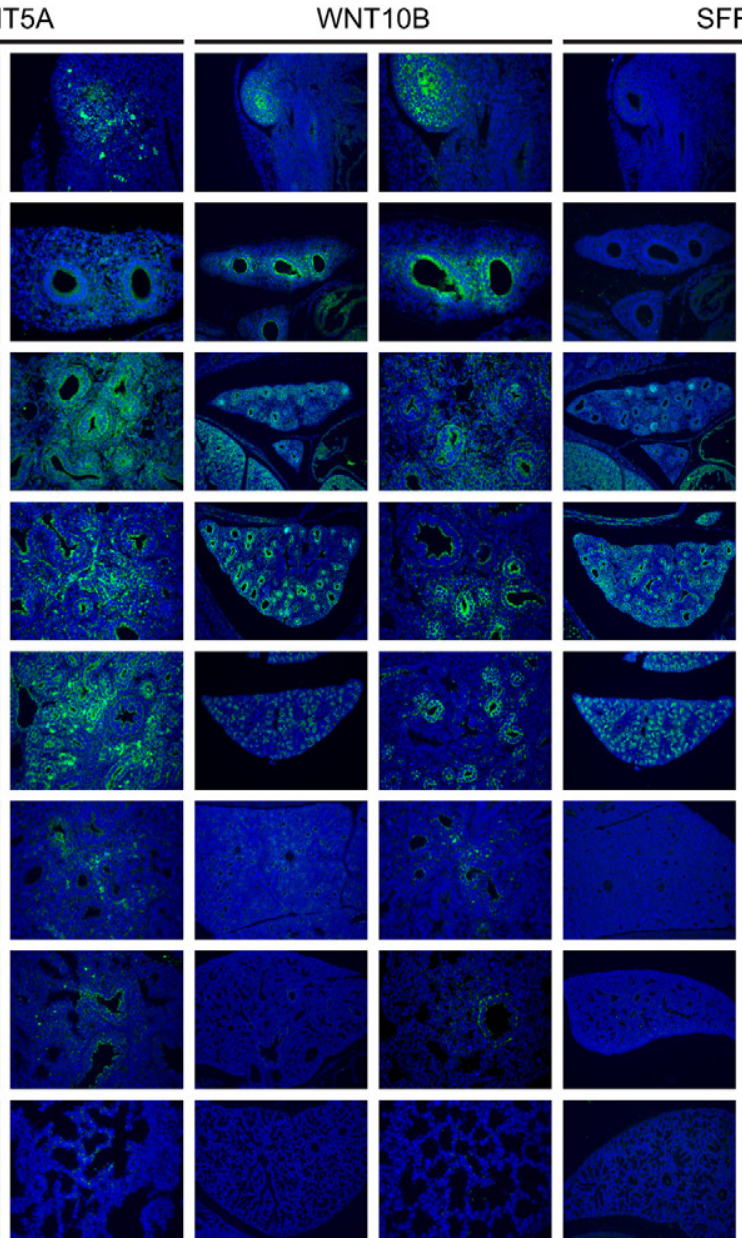

SFRP1
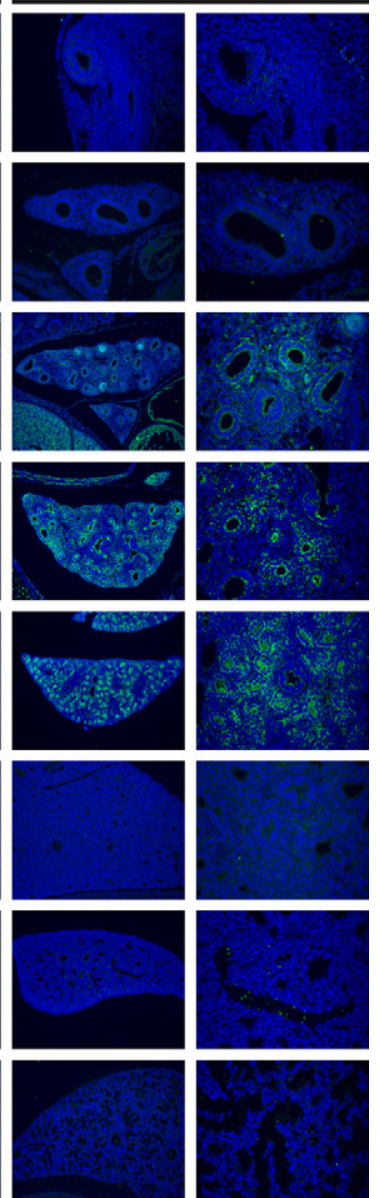

Figure 3. WNT5A, WNT10B and SFRP1 expression and protein levels during lung development. A: RT-PCR for Wnt5a, Wnt10b, Sfrp1 and GAPDH reveals expression of Wnt5a, Wnt10b, and Sfrp1 at embryonic stages (14.5, 16.5, and $18.5 \mathrm{dpc})$ but not later including newborn, five days post partum ( $5 \mathrm{pp})$, or fourteen weeks of age. B: Western blot analyses for WNT5A, WNT10B, and SFRP1 on mouse lung tissue protein reveals bands of appropriate molecular weight (43 kDa for WNT5A; $40 \mathrm{kDa}$ for WNT10B; $36 \mathrm{kDa}$ for SFRP1) present at $14.5 \mathrm{dpc}$, but not at 5 days post partum (5 pp). C: Using specific antibodies for WNT5A, WNT10B, and SFRP1, immunofluorescent analyses were performed on lung tissue sections from the lungs of mice during early lung development (10.5 to $18.5 \mathrm{dpc}$ ). H\&E staining was performed for comparison.

gressive; physiological measurements demonstrated that these architectural changes were not associated with changes in lung compliance (data not shown). Therefore, these findings in the knockout mice are consistent with a development defect and not with an ongoing destructive process.

\section{SFRP1 Regulates Mesenchymal Proliferation} During Lung Embryogenesis

Due to the general role SFRP1 is known to play in mesenchymal proliferation and differentiation, ${ }^{16}$ we hypothesized that the observed ductal dilatation in the adult mice 
A

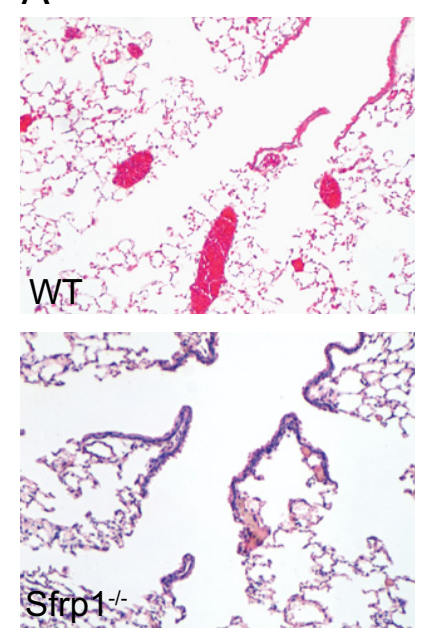

B

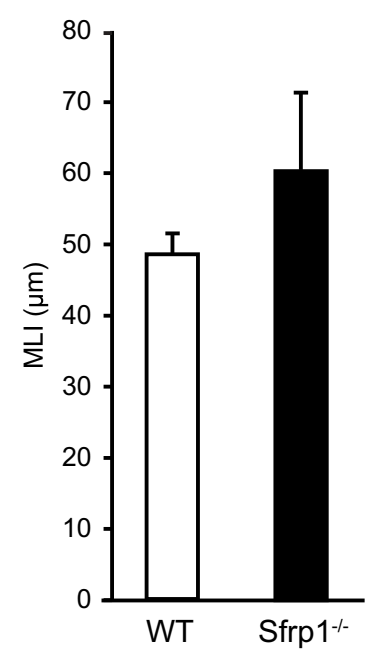

Figure 4. Sfrp1 alters distal lung development without affecting lung differentiation. A: At two months of age, the wild-type (WT) mice (upper) exhibited normal lung architecture. In contrast, the $\operatorname{Sfrp} 1^{-1-}$ mice (lower) exhibited dilatation of the alveolar duct. Similar findings were observed at the six-month and one-year time points. B: MLI of wild-type and $S f p 1^{-/-}$mice $(P=0.0028)$

may have resulted from a defect early in lung development in the mesenchymal component surrounding the forming ductal units. We therefore assessed the state of the mesenchymal component in the developing lung of Sfrp $1^{-1-}$ mice compared with wild-type. Morphologically the lungs of the Sfrp $1^{-1-}$ mice at $16.5 \mathrm{dpc}$ exhibit dilatation at the terminal ducts. Greater ductal dilatation continues to be seen in the lungs of the Sfrp $1^{-1-}$ mice at 18.5 $\mathrm{dpc}$, however as alveolar formation is initiated the difference between wild-type and Sfrp $1^{-1-}$ mice is grossly less obvious. Staining for smooth muscle actin was detected around the developing airways and blood vessels at 14.5 $\mathrm{dpc}$ in both the wild-type and the Sfrp $1^{-1-}$ mice. This staining intensified in the wild-type mice at $16.5 \mathrm{dpc}$; however, a marked decrease in staining was observed in the knockout mice at this time point (Figure 5). Of note, no difference in staining for elastin was detected between the groups at any of the time points tested (data not shown). We performed immunohistochemistry on lung tissue sections from wild-type and Sfrp $1^{-1-}$ mice using

antibodies raised against proximal (SCGB1A1; also known as CC10) and distal (SFTPA1; also known as SP-A and SFTPC; also known as SP-C) markers of lung epithelium. No differences were detected in staining between wild-type and Sfrp $1^{-1-}$ lung tissue for the proximal marker, CC10 (data not shown) or the distal lung markers, proteins SP-A and SP-C (data not shown). These results indicate that loss of Sfrp1 does not alter epithelial cell differentiation in proximal or distal structures in the developing lung despite the abnormality seen in smooth muscle cell content. Therefore, the loss of Sfrp1 alters normal lung development as early as $16.5 \mathrm{dpc}$ subsequently leading to abnormal formation of the alveolar duct.

\section{Increased $\beta$-Catenin in the Sfrp $1^{-/-}$Mice During Lung Development}

As shown above, expression of Sfrp1 is tightly regulated during lung development between $14.5 \mathrm{dpc}$ and 18.5 $\mathrm{dpc}$; therefore, we examined $\beta$-catenin levels during these time points to determine whether loss of Sfrp1 affected the canonical Wnt signaling pathway. Western blot analyses conducted on the lung tissue protein of embryonic and newborn mice demonstrated significantly enhanced nuclear translocation of $\beta$-catenin in the knockout mice at both 16.5 and $18.5 \mathrm{dpc}$ (Figure 6A). This increase was not seen in the newborn or adult lung (data not shown) as would be expected because Sfrp1 is not expressed in the adult. These results demonstrate that loss of Sfrp1 increased Wnt signaling through the canonical pathway during this embryonic time period leading to a defect in distal lung formation. Though the wild-type and Sfrp $1^{-1-}$ lungs were morphologically similar at E18.5, we assert that the impairments in cell signaling that occurred in the knockout mice during this time interval set the stage for the subsequent impairments in distal lung formation. Indeed, the defect in alveoli was evident as early as two weeks after birth.

\section{Altered Wnt Signaling in the Sfrp1 Knockout Mice During Lung Development}

To identify whether loss of Sfrp1 led to changes in Wnt signaling during embryogenesis, the expression of Wnt5a
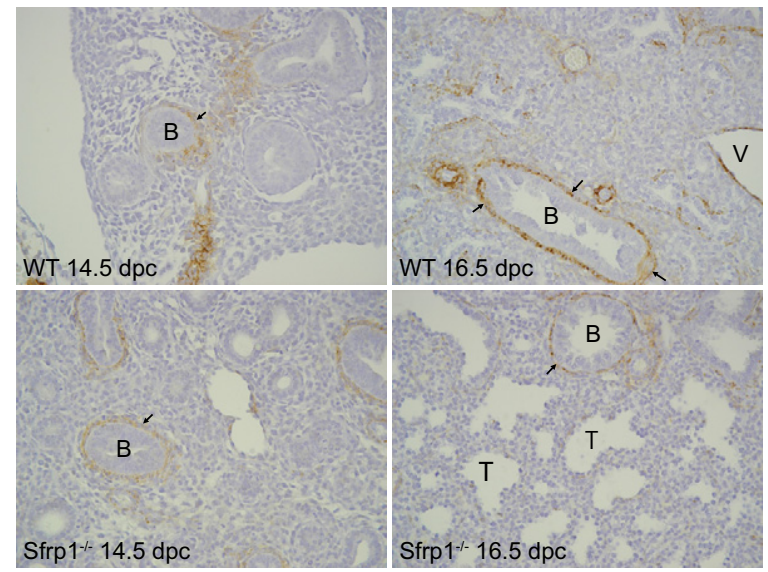

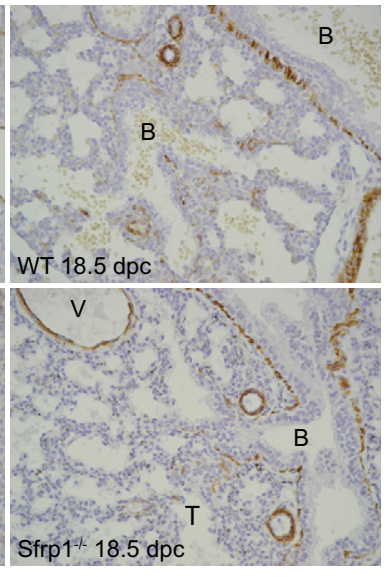

Figure 5. Altered lung formation in $S f r p 1^{-1-}$ mice. Lung sections of wild-type (WT) and Sfrp $1^{-/-}$mice at $14.5,16.5$, and $18.5 \mathrm{dpc}$ were examined and stained for SMA. Morphologically the lungs of the Sfrp $1^{-/-}$mice at $16.5 \mathrm{dpc}$ exhibit dilatation at the terminal ducts (T). Greater ductal dilatation continues to be seen in the lungs of the Sfrp $1^{-/-}$mice at 18.5 dpc compared with wild-type. Immunostaining for SMA demonstrated marked reduction of SMA-positive cells in the Sfrp $1^{-/-}$mice. The arrowheads indicates peribronchial smooth muscle cells. B indicates bronchus; $\mathrm{V}$, large vessel. 
A

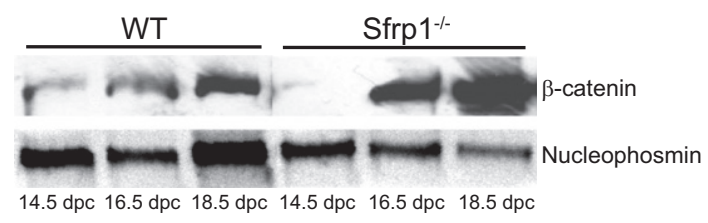

C

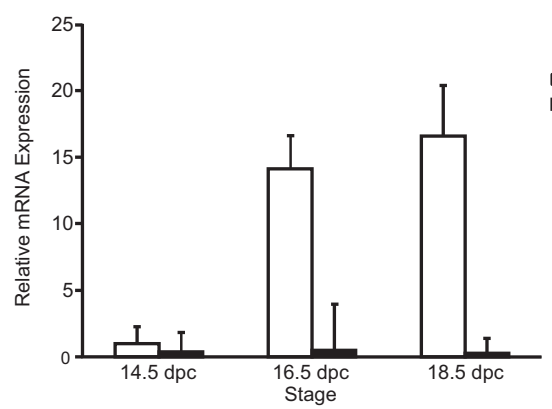

B
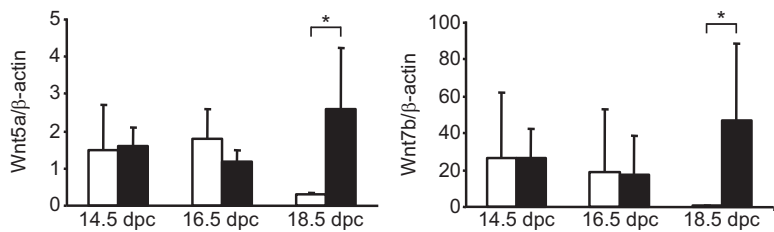

$\mathrm{D}$

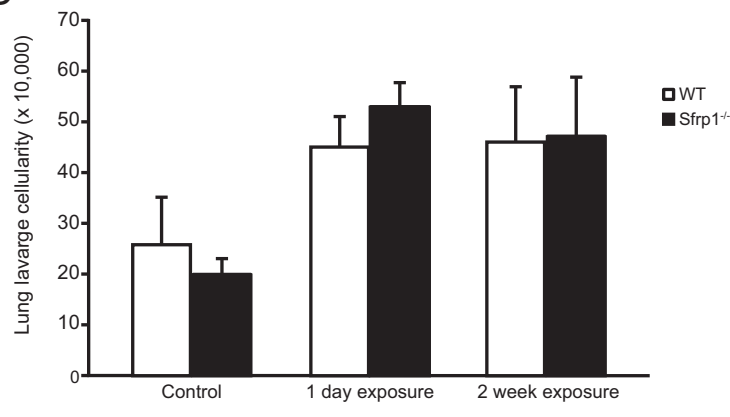

Figure 6. SFRP1 regulates Wnt signaling and mesenchymal development in the lung. A: Western blot for $\beta$-catenin was performed on the nuclear protein extracts of lung tissue obtained from $14.5,16.5$, and $18.5 \mathrm{dpc}$ wild-type (WT) and Sfrp1 ${ }^{-/-}$mice. Western blot for nucleophosmin was used as a protein loading control. $\beta$-catenin levels accumulated in the nucleus of $\operatorname{Srp} 1^{-/-}$mice when compared with wild-type. B: Using specific primers for mouse Wnt5a, Wnt $7 \mathrm{~b}$, and $\beta$-actin, SYBR Green quantitative PCR was performed on the RNA isolated from the lung tissue of wild-type (white bars) and Sfrp1 knockout mice (black bars) at embryonic day $14.5,16.5$, and 18.5. Expression levels for Wnt5a and Wnt7b were normalized for $\beta$-actin ( $y$ axis; $n=4$ in each group, $\left.{ }^{*} P<0.05\right)$. Expression of Wnt5a and Wnt7b are up-regulated in the $S f r p 1^{-/-}$mice at $18.5 \mathrm{dpc}$. C: Real-time RT-PCR analysis of mRNA from mice embryos. Compared with wild-type mice (white bar), Sfrp $1^{-1-}$ mice exhibited significant reduction of MMP9 mRNA expression. D: The number of inflammatory cells isolated from the lung lavage was determined for wild-type and $S f r p 1^{-1-}$ mice under control conditions or after 1 day or 2 weeks of cigarette smoke exposure. There is no difference between wild-type and knockout mice at all three time points.

and Wnt7b was examined. These Wnts were chosen because they are known to exert key effects on lung development. ${ }^{28}$ Wnt5a and Wnt7b expression were significantly increased by RT-PCR in the knockout mice at embryonic day 18.5 (Figure 6B). This increased expression in the knockout mice occurs during a period when Wnt expression is normally down-regulated in the developing lung (see Figure 3C).

\section{Sfrp $1^{-/-}$Mice Decreases MMP Expression in Lung}

Since the re-expression of SFRP1 in the adult tissue leads to up-regulation of MMP expression (Figure 2E), we examined whether Sfrp1 modulated MMP production during development. MMP9 levels were measured in mouse lungs from wild-type and Sfrp $1^{-1-}$ mice. As shown in Figure 6C, Sfrp $1^{-1-}$ mice exhibited decreased MMP9 expression at 16.5 and $18.5 \mathrm{dpc}$ when it was normally highly expressed in developing lung of the wild-type mice $\left(P=0.0011\right.$; wild-type versus Sfrp $\left.1^{-1-}\right)$. There was no significant difference in TIMP1 expression levels (data not shown). Thus, SFRP1 correlates positively with MMP expression in both the adult and developing lung. While the presence of SFRP1 expression in adult SAE cells up-regulated lung proteases, the lack of Sfrp1 expression during embryogenesis in the knockout mice resulted in inappropriately low MMP lung levels. These findings denote a previously unknown role of SFRP1 in the regulation of lung protease expression.

\section{SFRP1 Does Not Alter Inflammation in Response to Cigarette Smoke Exposure}

Given its induction in emphysema, we aimed to determine whether SFRP1 altered the inflammatory response of the lung to acute or subacute smoke exposure. To do so, we exposed wild-type and Sfrp $1^{-1-}$ mice to one day (acute) and two weeks (subacute) of cigarette smoke exposure. These studies demonstrated that cigarette smoke generated an equivalent increase in lung lavage cellularity in the wild-type and Sfrp $1^{-1-}$ mice (Figure 6D). Similar findings were seen after four months (chronic) of smoke exposure (data not shown).

\section{Discussion}

The expression of developmental genes in the adult lung is theorized to be part of a well-orchestrated maintenance program to preserve structural integrity. Specifically, the repair/regeneration process initiated in response to lung injury is believed to recapitulate mechanisms involved in normal lung morphogenesis. ${ }^{29,30}$ The findings from the present study suggest, however, that the developmental gene Sfrp1 exerts distinct effects in the adult lung from those that occur during lung morphogenesis. Here we demonstrate that loss of Sfrp1 disrupts proper alveolar formation by regulating Wnt signaling and mesenchymal growth and turnover during lung development, its expression in the adult lung induces proteases known to lead to tissue destruction and emphysema formation. ${ }^{18,31,32}$ 
SFRP1 up-regulated MMP1 and MMP9 production in both pneumocytes and small airway epithelial cells. This is significant because the small airways are the site of an intense inflammatory and remodeling process that results in severe airway obstruction in emphysema. ${ }^{33}$ Furthermore, MMP1 and MMP9 have been linked to emphysema in both animal models ${ }^{24,31}$ and patients. ${ }^{34,35}$ The induction of MMP1 by cigarette smoke is dependent on ERK activation. ${ }^{23}$ In this study, SFRP1 activated ERK and induced MMP1 expression within the lung epithelium. Thus, it reproduces biological processes that are linked to the development of cigarette smoke-induced emphysema. ${ }^{23}$ Indeed, this is the first study to demonstrate that SFRPs, inhibitors of WNT, directly up-regulate the expression of MMPs. Prior research had shown that WNTs and nuclear translocation of $\beta$-catenin stimulate MMP7 production, ${ }^{36,37}$ while the WNT antagonists SFRP3 and DKK1 inhibit MMP expression. ${ }^{38,39}$ In addition, it was recently discovered that SFRPs directly inhibit the activity of the metalloproteinase Xolloid-related (XIr). ${ }^{40}$ Our data coupled with these previous findings indicate that the regulation of individual MMPs by the WNT signaling pathways is complex. Our study demonstrates that proteases known to play a key role in the pathogenesis of emphysema are up-regulated by SFRP1. While in the adult lung this would lead to lung tissue destruction, the induction of lung proteases during development likely allows proper alveolar formation to occur. Therefore, the absence of SFRP1 during embryogenesis would impair protease-dependent tissue remodeling, thus resulting in alveolar ductal dilation. This is consistent with our finding of decreased MMP expression in the lung during embryonic development in the Sfrp1-1- mice.

As early as two weeks of age, the deficiency in Sfrp1 resulted in dilated alveolar ducts in the knockout mice when compared with wild-type littermate mice. This defect did not progress over time, indicating that it resulted from events that occurred specifically during lung morphogenesis. Indeed, Sfrp1 expression was detected in the lung only during a defined period of embryogenesis and most predominantly in the mesenchyme and distal lung structures beginning at $16.5 \mathrm{dpc}$ and ending 18.5 dpc. The absence of Sfrp1 expression in the Sfrp $1^{-1-}$ mice enhanced nuclear translocation of $\beta$-catenin, resulting in dysregulation of the mesenchyme and deficient alveolar formation. $\beta$-catenin, the central target of the canonical pathway, is detected in the lung epithelium and surrounding mesenchyme during lung development. ${ }^{41}$ Recently, the loss of $\beta$-catenin expression during lung morphogenesis was shown to severely impair the formation of distal airway structures. ${ }^{42}$ Furthermore, aberrant $\beta$-catenin activation in pulmonary fibrosis was associated with cellular hyperplasia and honeycombing of the lung. ${ }^{7}$ Given the central role of $\beta$-catenin in distal lung development, the changes in $\beta$-catenin nuclear translocation observed in the Sfrp $1^{-1-}$ mice likely exerted an important role in the aberrant mesenchymal growth and deficient alveolar formation that occurred in these mice.

Multiple components of the Wnt signaling pathway have been implicated to play a role in lung formation. ${ }^{43,44}$ The loss of Wnt5a expression in mice causes overexpan- sion of the distal epithelial airways and thickening of the mesenchymal interstitium. ${ }^{25}$ Conversely, the transgenic expression of Wnt5a during early lung development resulted in decreased epithelial branching and dilation of the distal airways. ${ }^{45}$ Wnt7b knockout mice exhibited mesenchymal proliferation that led to the development of hypoplastic lungs. ${ }^{10}$ This is the first description of a lung development phenotype attributable to the loss of an SFRP. Given the known effects of WNTs on lung morphogenesis, it is conceivable that the disruption of the distal lung formation in the knockout mice was a consequence of aberrant Wht expression. Our immunofluorescence studies demonstrated that Sfrp1 and WNT5A colocalize to the developing mesenchyme during embryogenesis. Thus, the dysregulation of Wnt5a in the knockout mice may well have contributed to the abnormal mesenchymal proliferation and deficient actin synthesis observed in the lung.

The loss of alveolar tissue in emphysema greatly impairs gas exchange and physiological function in affected patients. Retinoic acid, a dietary element that is crucial in lung formation, reverses elastase-induced emphysema in rodents. ${ }^{46}$ These findings have sparked interest in treatment strategies aimed at inducing developmental processes to reverse the destructive changes seen in emphysema. ${ }^{47}$ We identified the selective upregulation of SFRP1 in human emphysema. However, rather than serving a reparative role, our results indicate that expression of this developmental gene in the adult lung triggers destructive mechanisms that results in the loss of lung tissue. Future studies will explore whether long-term expression of SFRP1 in vivo leads to matrix loss and emphysema formation. If so, targeting SFRP1 with pharmacotherapy may counteract the damaging processes that are a central component of this disease.

\section{References}

1. Steiling $H$, Werner S: Fibroblast growth factors: key players in epithelial morphogenesis, repair and cytoprotection. Curr Opin Biotechnol 2003, 14:533-537

2. Devarajan P, Mishra J, Supavekin S, Patterson LT, Steven Potter S: Gene expression in early ischemic renal injury: clues towards pathogenesis, biomarker discovery, and novel therapeutics. Mol Genet Metab 2003, 80:365-376

3. Zhao P, Hoffman EP: Embryonic myogenesis pathways in muscle regeneration. Dev Dyn 2004, 229:380-392

4. Voelkel NF, Vandivier RW, Tuder RM: Vascular endothelial growth factor in the lung. Am J Physiol Lung Cell Mol Physiol 2006, 290:L209-L221

5. Otu HH, Naxerova K, Ho K, Can H, Nesbitt N, Libermann TA, Karp SJ: Restoration of liver mass after injury requires proliferative and not embryonic transcriptional patterns. J Biol Chem 2007 282:11197-11204

6. Parkin CA, Ingham PW: The adventures of Sonic Hedgehog in development and repair. I Hedgehog signaling in gastrointestinal development and disease, Am J Physiol Gastrointest Liver Physiol 2008, 294:G363-G367

7. Chilosi M, Poletti V, Zamo A, Lestani M, Montagna L, Piccoli P, Pedron S, Bertaso M, Scarpa A, Murer B, Cancellieri A, Maestro R, Semenzato G, Doglioni C: Aberrant Wnt/beta-catenin pathway activation in idiopathic pulmonary fibrosis. Am J Pathol 2003, 162:1495-1502

8. Kuhl M, Sheldahl LC, Malbon CC, Moon RT: Ca(2+)/calmodulindependent protein kinase $\mathrm{II}$ is stimulated by Wnt and Frizzled ho- 
mologs and promotes ventral cell fates in Xenopus. J Biol Chem 2000, 275:12701-12711

9. Boutros M, Paricio N, Strutt DI, Mlodzik M: Dishevelled activates JNK and discriminates between JNK pathways in planar polarity and wingless signaling. Cell 1998, 94:109-118

10. Shu W, Jiang YQ, Lu MM, Morrisey EE: Wnt7b regulates mesenchymal proliferation and vascular development in the lung. Development 2002, 129:4831-4842

11. Cardoso WV, Lu J: Regulation of early lung morphogenesis: questions, facts and controversies. Development 2006, 133:1611-1624

12. Okubo T, Hogan BL: Hyperactive Wnt signaling changes the developmental potential of embryonic lung endoderm. J Biol 2004, 3:11

13. Uren A, Reichsman F, Anest V, Taylor WG, Muraiso K, Bottaro DP, Cumberledge S, Rubin JS: Secreted frizzled-related protein-1 binds directly to Wingless and is a biphasic modulator of Wnt signaling J Biol Chem 2000, 275:4374-4382

14. Tebar M, Destree O, de Vree WJ, Ten Have-Opbroek AA: Expression of Tcf/Lef and sFrp and localization of beta-catenin in the developing mouse lung. Mech Dev 2001, 109:437-440

15. Konigshoff M, Kramer M, Balsara N, Wilhelm J, Amarie OV, Jahn A, Rose F, Fink L, Seeger W, Schaefer L, Gunther A, Eickelberg O: WNT1-inducible signaling protein-1 mediates pulmonary fibrosis in mice and is upregulated in humans with idiopathic pulmonary fibrosis. J Clin Invest 2009, 119:772-787

16. Bodine PV, Zhao W, Kharode YP, Bex FJ, Lambert AJ, Goad MB, Gaur T, Stein GS, Lian JB, Komm BS: The Wnt antagonist secreted frizzled-related protein-1 is a negative regulator of trabecular bone formation in adult mice. Mol Endocrinol 2004, 18:1222-1237

17. Foronjy RF, Mercer BA, Maxfield MW, Powell CA, D'Armiento J, Okada Y: Structural emphysema does not correlate with lung compliance: lessons from the mouse smoking model. Exp Lung Res 2005, 31:547-562

18. D'Armiento J, Dalal SS, Okada Y, Berg RA, Chada K: Collagenase expression in the lungs of transgenic mice causes pulmonary emphysema. Cell 1992, 71:955-961

19. Tang SC, Sambanis A: Development of genetically engineered human intestinal cells for regulated insulin secretion using rAAVmediated gene transfer. Biochem Biophys Res Commun 2003, 303:645-652

20. Foronjy RF, Mirochnitchenko O, Propokenko O, Lemaitre V, Jia $Y$, Inouye M, Okada Y, D'Armiento JM: Superoxide dismutase expression attenuates cigarette smoke- or elastase-generated emphysema in mice. Am J Respir Crit Care Med 2006, 173:623-631

21. Heussen C, Dowdle E: Electrophoretic analysis of plasminogen activators in polyacrylamide gels containing sodium dodecyl sulfate and copolymerized substrates. Anal Biochem 1980, 102:196-202

22. Elkington PT, Friedland JS: Matrix metalloproteinases in destructive pulmonary pathology. Thorax 2006, 61:259-266

23. Mercer B, Kolesnikova N, Sonett J, D'Armiento J: Extracellular regulated kinase/mitogen activated protein kinase is up-regulated in pulmonary emphysema and mediates matrix metalloproteinase- 1 induction by cigarette smoke. J Biol Chem 2004, 279:17690-17696

24. Foronjy RF, Okada Y, Cole R, D’Armiento J: Progressive adult-onset emphysema in transgenic mice expressing human MMP-1 in the lung. Am J Physiol Lung Cell Mol Physiol 2003, 284:L727-L737

25. Li C, Xiao J, Hormi K, Borok Z, Minoo P: Wnt5a participates in distal lung morphogenesis. Dev Biol 2002, 248:68-81

26. Bennett CN, Longo KA, Wright WS, Suva LJ, Lane TF, Hankenson KD, MacDougald OA: Regulation of osteoblastogenesis and bone mass by Wnt10b. Proc Natl Acad Sci U S A 2005, 102:3324-3329

27. Bennett CN, Ross SE, Longo KA, Bajnok L, Hemati N, Johnson KW, Harrison SD, MacDougald OA: Regulation of Wht signaling during adipogenesis. J Biol Chem 2002, 277:30998-31004

28. Aoki K, Taketo M: Tissue-specific transgenic, conditional knockout and knock-in mice of genes in the canonical Wnt signaling pathway. Methods Mol Biol 2008, 468:307-331

29. Douglas IS, Diaz del Valle F, Winn RA, Voelkel NF: Beta-catenin in the fibroproliferative response to acute lung injury. Am J Respir Cell Mol Biol 2006, 34:274-285
30. Taraseviciene-Stewart L, Voelkel NF: Molecular pathogenesis of emphysema. J Clin Invest 2008, 118:394-402

31. Foronjy R, Nkyimbeng T, Wallace A, Thankachen J, Okada Y, Lemaitre V, D'Armiento J: Transgenic expression of matrix metalloproteinase- 9 causes adult-onset emphysema in mice associated with the loss of alveolar elastin. Am J Physiol Lung Cell Mol Physiol 2008, 294:L1149-L1157

32. Tuder RM, Zhen L, Cho CY, Taraseviciene-Stewart L, Kasahara Y, Salvemini D, Voelkel NF, Flores S: Oxidative Stress and Apoptosis Interact and Cause Emphysema Due to Vascular Endothelial Growth Factor Receptor Blockade. Am J Resp Cell Mol Biol 2003, 29:88-97

33. Hogg JC, Chu F, Utokaparch S, Woods R, Elliott WM, Buzatu L, Cherniack RM, Rogers RM, Sciurba FC, Coxson HO, Pare PD: The nature of small-airway obstruction in chronic obstructive pulmonary disease. N Engl J Med 2004, 350:2645-2653

34. Imai K, Dalal SS, Chen ES, Downey R, Schulman LL, Ginsburg M, D'Armiento J: Human collagenase (matrix metalloproteinase-1) expression in the lungs of patients with emphysema. Am J Respir Crit Care Med 2001, 163:786-791

35. Russell RE, Culpitt SV, DeMatos C, Donnelly L, Smith M, Wiggins J, Barnes PJ: Release and activity of matrix metalloproteinase-9 and tissue inhibitor of metalloproteinase- 1 by alveolar macrophages from patients with chronic obstructive pulmonary disease. Am J Respir Cell Mol Biol 2002, 26:602-609

36. Matono H, Oda Y, Nakamori M, Tamiya S, Yamamoto H, Yokoyama R, Saito T, Iwamoto Y, Tsuneyoshi M: Correlation between beta-catenin widespread nuclear expression and matrix metalloproteinase-7 overexpression in sporadic desmoid tumors. Hum Pathol 2008, 39:18021808

37. Lyu J, Joo CK: Wnt-7a up-regulates matrix metalloproteinase-12 expression and promotes cell proliferation in corneal epithelial cells during wound healing. J Biol Chem 2005, 280:21653-21660

38. Zi X, Guo Y, Simoneau AR, Hope C, Xie J, Holcombe RF, Hoang BH Expression of Frzb/secreted Frizzled-related protein 3, a secreted Wnt antagonist, in human androgen-independent prostate cancer PC-3 cells suppresses tumor growth and cellular invasiveness. Cancer Res 2005, 65:9762-9770

39. Pukrop T, Klemm F, Hagemann T, Gradl D, Schulz M, Siemes S, Trumper L, Binder C: Wnt 5 a signaling is critical for macrophageinduced invasion of breast cancer cell lines. Proc Natl Acad Sci U S A 2006, 103:5454-5459

40. Lee HX, Ambrosio AL, Reversade B, De Robertis EM: Embryonic dorsal-ventral signaling: secreted frizzled-related proteins as inhibitors of tolloid proteinases. Cell 2006, 124:147-159

41. Eberhart CG, Argani P: Wnt signaling in human development: betacatenin nuclear translocation in fetal lung, kidney, placenta, capillaries, adrenal, and cartilage. Pediatr Dev Pathol 2001, 4:351-357

42. Mucenski ML, Wert SE, Nation JM, Loudy DE, Huelsken J, Birchmeier W, Morrisey EE, Whitsett JA: beta-Catenin is required for specification of proximal/distal cell fate during lung morphogenesis. J Biol Chem 2003, 278:40231-40238

43. Wang Z, Shu W, Lu MM, Morrisey EE: Wnt7b activates canonical signaling in epithelial and vascular smooth muscle cells through interactions with Fzd1. Fzd10, and LRP5. Mol Cell Biol 2005, 25:5022-5030

44. Shu W, Guttentag S, Wang Z, Andl T, Ballard P, Lu MM, Piccolo S, Birchmeier W, Whitsett JA, Millar SE, Morrisey EE: Wnt/beta-catenin signaling acts upstream of N-myc. BMP4, and FGF signaling to regulate proximal-distal patterning in the lung. Dev Biol 2005, 283:226-239

45. Li C, Hu L, Xiao J, Chen H, Li JT, Bellusci S, Delanghe S, Minoo P: Wnt5a regulates Shh and Fgf10 signaling during lung development. Dev Biol 2005, 287:86-97

46. Massaro GD, Massaro D: Retinoic acid treatment abrogates elastaseinduced pulmonary emphysema in rats. Nat Med 1997, 3:675-677

47. Roth MD, Connett JE, D'Armiento JM, Foroniy RF, Friedman PJ, Goldin JG, Louis TA, Mao JT, Muindi JR, O'Connor GT, Ramsdell JW, Ries AL, Scharf SM, Schluger NW, Sciurba FC, Skeans MA, Walter $\mathrm{RE}$, Wendt $\mathrm{CH}$, Wise RA: Feasibility of retinoids for the treatment of emphysema study. Chest 2006, 130:1334-1345 